\title{
Estádios de desenvolvimento dos órgãos reprodutivos dos machos de Panulirus echinatus Smith (Decapoda: Palinuridae)
}

\author{
Aline do V. Barreto ${ }^{1} \&$ Mario Katsuragawa ${ }^{2}$ \\ 1 Departamento de Oceanografia, Universidade Federal de Pernambuco. Avenida Arquitetura, Cidade Universitária, \\ 50670-901 Recife, Pernambuco, Brasil. E-mail: avb@ufpe.br \\ 2 Instituto Oceanográfico, Universidade de São Paulo. Praça do Oceanográfico 191, Butantã, 05508-900 São Paulo, São \\ Paulo, Brasil.
}

\begin{abstract}
Development stages of the reproductive tract of male of Panulirus echinatus Smith (Decapoda: Palinuridae). This paper characterizes the developmental stages of the testes and vasa deferentia of the Panulirus echinatus Smith, 1869 through comparisons between microscopic findings, macroscopic aspects, and gonadosomatic index (GSR). The lobsters were sampled monthly (November 1999 to October 2000) using seine nets and a total of 1716 males were obtained at Tamandaré Bay. Each carapace was cut to allow evaluation of the reproductive organs; the testes and vasa deferentia were dissected, weighed, fixed in Bouin's solution up to 12 hours and submitted for histological analysis to determine the presence and/or absence of spermatozoa. These measures, along with change in color, size, diameter, development of the spermatophores and the GSR allowed the caracterization of three development stages: immature, intermediate and ripe. In conclusion, the maturity of the testes precedes the maturity of the vasa deferentia. To evaluate if gonadosomatic relation was a good quantitative indicator of the maturity stage, $t$ tests $(\alpha=0,05)$ were used and verified significant difference in the averages of GSR. The statistics corroborated that GSR can be used as indicative of the developmental stages for $P$. echinatus.
\end{abstract}

KEY WORDS. Gonadosomatic relation; histology; reproduction.

RESUMO. Esta pesquisa caracteriza os estádios de desenvolvimento dos testículos e canais deferentes da lagosta Panulirus echinatus Smith, 1869 a partir da relação entre seus aspectos macroscópicos, microscópicos e a relação gonadossomática (RGS). Através de amostragem mensal (novembro de 1999 a outubro de 2000) foram capturados 1716 machos, empregando-se redes de espera de fundo. Retirou-se a região dorsal da carapaça para avaliação dos órgãos reprodutivos. Os testículos e canais deferentes foram dissecados, pesados, fixados em solução de Bouin e submetidos aos procedimentos histológicos. A análise microscópica dos órgãos reprodutivos foi avaliada pela presença ou ausência de espermatozóides nos testículos e canais deferentes. Esta, quando associada a macroscopia (mudança de cor, tamanho, diâmetro e desenvolvimento de espermatóforo) e a relação gonadossomática (RGS), possibilitou a caracterização de três estádios de desenvolvimento: imaturo, intermediário e maturo. Ficou evidenciada que a maturidade dos testículos precedeu a maturidade dos canais deferentes. Para avaliar se a RGS é um bom indicador quantitativo dos estádios de maturidade, um teste $\mathrm{t}(\alpha=0,05)$ foi usado e constatou diferença significativa nas médias da RGS. A RGS pode ser utilizada como indicadora dos estádios de maturidade para $P$. echinatus. PALAVRAS-CHAVE. Histologia; relação gonadossomática; reprodução.

Panulirus echinatus Smith, 1869, (Palinuridae) conhecida como lagosta pintada, distribui-se no Atlântico Ocidental (Ceará até Rio de Janeiro) e nos Arquipélagos de São Pedro e São Paulo, Fernando de Noronha, Atol das Rocas e Ilha de Trindad; no Atlântico Central (Ascenção e Cabo Verde) e Atlântico Oriental (Ilhas Canárias e de Cabo Verde) (Holthuis 1991, Melo 1999). Esta espécie é um importante objeto de estudo, não só por sua abundância em áreas costeiras e Ilhas oceânicas, mas, sobretudo por ser uma apreciável fonte de alimento.
A reprodução é um dos aspectos mais importantes no ciclo de vida de uma espécie. O conhecimento das escalas de maturidade em que os indivíduos de uma determinada espécie completam o desenvolvimento de seus gametas são metas importantes no estudo de um recurso pesqueiro de valor comercial. A necessidade de se conhecer a biologia reprodutiva de $P$. echinatus surgiu em virtude da espécie em questão está sendo explorada nos recifes costeiros do Nordeste do Brasil e em particular em Tamandaré, Pernambuco.

Revista Brasileira de Zoologia 25 (1): 74-82, March, 2008 
Devido à ausência de estudos mais específicos sobre o desenvolvimento dos órgãos reprodutivos dos machos da lagosta P. echinatus, foram consultadas as publicações de LindBERG 1955, Mota Alves \& Tomé $(1965,1966 a)$ que trabalhando com as lagostas Panulirus interruptus (Randall, 1840) e Panulirus laevicauda (Latreille, 1817) respectivamente, basearam a estimativa da maturidade gonadal dos machos destas espécies na presença de espermatozóides nos testículos. Heydorn (1969), entretanto pesquisando o aparelho reprodutor de Panulirus homarus (Linnaeus, 1758) afirmou que o estádio de desenvolvimento dos canais deferentes dá uma indicação do início de maturidade gonadal.

Escalas de maturidade baseadas em características macro e microscópicas das gônadas e na relação gonadossomática (RGS) ou índice gonadossomático (IGS) são instrumentos utilizados para avaliar o desenvolvimento gonadal de uma dada espécie (IsAaC-NAHUM \& VAZzoler 1987, VAZZOler et al. 1989a,b, KoA-JeN 1993, Vazzoler 1996, CAstiglioni et al. 2006, SoKolowicz et al. 2006). Por um rigor matemático, no presente trabalho, o indicador quantitativo de maturidade é tratado como uma relação. A RGS expressa a porcentagem que as gônadas representam do peso total ou do peso corporal dos indivíduos (VAzzoler 1996). A partir dessas observações, podem-se estabelecer futuros manejos embasados em estudos de maturidade utilizando o trato reprodutor, sobretudo o canal deferente que secreta, guarda e expele o espermatóforo. Nas lagostas da família Palinuridae, durante o acasalamento, o macho transfere o espermatóforo sobre a superfície ventral das fêmeas, próximo à abertura do oviduto, portanto a fecundação é externa. Segundo BERRY \& Heydorn (1970), RAdHa \& Subramoniam (1985) e Martin et al. (1987) que estudaram as lagostas da família Palinuridae, os espermatozóides são transferidos através do espermatóforo, que é uma massa complexa consistindo de três componentes: um tubo espermatofórico envolto em uma matriz acelular adesiva basal e uma matriz gelatinosa protetora. MARTIN et al. (1987) relataram que a superfície côncava do espermatóforo formará a capa do espermatóforo ejaculado e a superfície convexa formará o pé que se prenderá no esterno da fêmea. Estes autores concluíram que os espermatóforos são especializados para o transporte, manutenção e lançamento de espermatozóides e que as variações nas estruturas espermatofóricas refletem diferenças no mecanismo de fertilização dentro dos crustáceos. Estudos sobre o espermatóforo de lagostins foram realizados por DudENHAusen $\&$ TAlbot (1983) е TаLвот \& BEACH (1989). Eles relataram que a massa de esperma é composta de espermatozóides e de espermátides. Kooda-Cisco \& Talbot (1986) e Hinsch \& McKnight (1988) além de detalharem o trato reprodutor da lagosta Homarus americanus (H. Milne-Edwards, 1837) (Nephropidae) e Scyllarus chacei Holthuis, 1960 (Scyllaridae) respectivamente, estudaram também, a formação dos espermatóforos. Em todas as lagostas e lagostins, o trato reprodutivo apresentou-se em forma de $\mathrm{H}$.

A presente pesquisa constitui a primeira contribuição sobre os estádios de desenvolvimento dos órgãos reprodutivos dos machos da lagosta P. echinatus utilizando os testículos e, sobretudo os canais deferentes. O objetivo é caracterizar os estádios de desenvolvimento dos testículos e canais deferentes de P. echinatus, analisando-se seus aspectos macroscópicos, microscópicos e a relação gonadossomática (RGS). A caracterização dos estádios é a proposta básica para uma futura administração pesqueira deste recurso de importância econômica. O grande esforço de captura, entretanto, foi necessário para se ter um tamanho da amostra adequada para identificar o período reprodutivo da espécie, em uma outra publicação.

\section{MATERIAL E MÉTODOS}

A baía de Tamandaré é uma enseada relativamente arredondada, com cerca de $4 \mathrm{~km}^{2}$, destacando-se por possuir uma linha de recifes orgânicos, separando-a do mar aberto e constituindo um "quebra mar" natural. Está localizada aproximadamente a $110 \mathrm{~km}$ ao sul da cidade de Recife, Pernambuco, entre $08^{\circ} 45^{\prime} 36^{\prime \prime}-08^{\circ} 47^{\prime} 20^{\prime \prime} \mathrm{S}$ e $35^{\circ} 05^{\prime} 45^{\prime \prime}-35^{\circ} 06^{\prime} 45^{\prime \prime} \mathrm{W}$ (Fig. 1). A baía possui profundidade média de $7 \mathrm{~m}$, tendo uma queda suave até a isóbata de 10 m, na saída da boca da barra (ReBouçAs 1966, Mabessone \& Coutinho 1970).

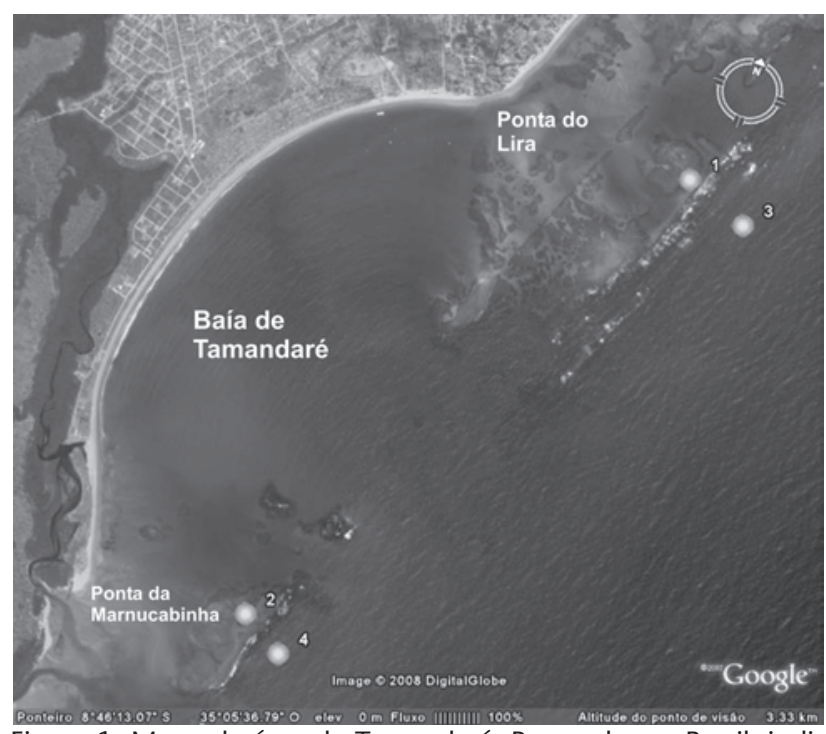

Figura 1. Mapa da área de Tamandaré, Pernambuco, Brasil, indicando os locais de coleta.

Seguindo um plano de amostragem mensal, entre novembro de 1999 e outubro de 2000, foram capturados 1716 machos, empregando-se redes de espera de fundo (rede de emalhar). As lagostas foram coletadas em quatro pontos: dois localizados nos recifes emersos por ocasião da baixa maré e dois nos recifes submersos, situados acerca de 330 e $250 \mathrm{~m}$, da linha de recifes que se volta para o mar aberto. Sendo as lagos-

Revista Brasileira de Zoologia 25 (1): 74-82, March, 2008 
tas animais notífagos (Holthus 1991), os lançamentos das redes de espera ocorreram antes do anoitecer e o recolhimento ao amanhecer.

Inicialmente as lagostas foram mensuradas com um paquímetro de aço, aferindo-se o comprimento da carapaça em $\mathrm{mm}$ e pesadas em uma balança digital com precisão de décimos de grama. A exposição dos órgãos reprodutivos foi realizada cortando-se ao longo da região lateral da carapaça, a partir da margem posterior do cefalotórax seguindo em direção aos espinhos supra-oculares. Em seguida, retirou-se toda a região dorsal do exoesqueleto cefalotorácico. Inicialmente, procedeuse a observação macroscópica através da coloração e aspectos relacionados ao tamanho e diâmetro do trato reprodutor de exemplares anestesiados com gelo. Os testículos e canais deferentes foram dissecados para pesagem (em balança analítica com precisão de décimos de milésimos de grama) e estudo microscópico, fixados em solução de Bouin por no máximo 12 horas e em seguida transferidos para álcool etílico a 70\%. Seções da porção posterior dos testículos e da porção mais dilatada do canal deferente foram desidratadas numa seqüência gradual de álcool etílico a diferentes diluições, clarificadas em xilol e incluídas em parafina. Posteriormente foram realizados cortes longitudinais e transversais com $5 \mu \mathrm{m}$ de diâmetro e corados com hematoxilina e eosina (JunqueIRA \& CARNeIro 1995).

A análise microscópica dos órgãos reprodutivos foi realizada considerando-se a presença ou ausência de espermatozóides nos testículos (túbulos seminíferos e ductos coletores) e na região mais dilatada dos canais deferentes. A análise macroscópica foi realizada através das modificações (cor, tamanho e diâmetro do espermatóforo) apresentadas no trato reprodutor dos indivíduos frescos ao longo dos estádios de desenvolvimento. Além da análise histológica e macroscópica dos testículos e canais deferentes, foram avaliados os indicadores quantitativos de maturidade estimando-se os valores médios da relação gonadossomática (RGS) por estádio de desenvolvimento (VAzzoler 1996) para um total de 1716 machos. A relação gonadossomática calculada para cada exemplar foi definida como: $\mathrm{RGS}=(\mathrm{Wg} / \mathrm{Wc}) \mathrm{x}$ 100. Sendo $\mathrm{Wc}=\mathrm{Wt}-\mathrm{Wg}$, onde $\mathrm{Wg}=$ peso úmido dos órgãos reprodutivos, $\mathrm{Wc}=$ peso úmido do corpo e $\mathrm{Wt}=$ peso total.

Para avaliar se a RGS é um bom indicador quantitativo de maturidade, foram estimadas suas médias nos diferentes estádios de desenvolvimento, e, para verificar possíveis diferenças entre as mesmas, foi empregada uma análise estatística através do programa Minitab. Esta análise foi baseada em um teste de hipótese de igualdade entre médias, no qual uma hipótese nula $H_{0}: \mu_{2}=\mu_{3}$ (as médias da RGS dos estádios II e III são iguais) foi confrontada contra uma hipótese alternativa $\mathrm{H}_{1}$ : $\mu_{2} \neq \mu_{3}$ (as médias da RGS dos estádios II e III são diferentes). O estádio I não foi considerado na comparação das médias devido ao pequeno número de elementos em sua amostra (apenas dois), o que fere a suposição de normalidade envolvida no teste. Na verificação de diferenças nas médias da RGS foi aplicado o teste t em nível de significância de $\alpha=0,05$.

\section{RESULTADOS}

O trato reprodutor do macho de P. echinatus localiza-se na região dorsal e mediana do cefalotórax, consistindo internamente de um par de testículos (glândulas), unidos por uma comissura, um par de canais deferentes e uma abertura genital (gonóporo) situada na base da coxa do quinto par de pereiópodo. Os testículos iniciam abaixo do pedúnculo ocular e ladeiam o estômago. Avançam abaixo do coração e seguem contornando o intestino, alçando o segmento abdominal. Os canais deferentes foram diferenciados em três porções: a mais estreita, ou anterior, que se apresenta espiralada e pelas porções mais largas, mediana e distal; esta se estende até o gonóporo.

As análises microscópicas dos testículos possibilitaram a visualização de um túbulo seminífero com aspecto altamente convoluto e ductos coletores. No túbulo seminífero seccionado foram observadas as células germinativas (espermatogônias, espermatócitos, espermátides e espermatozóides). As duas primeiras células germinativas e as células sustentaculares bordeiam a parede interna do túbulo seminífero, enquanto as espermátides e espermatozóides ocupam o lume do túbulo. A microscopia dos órgãos reprodutores foi avaliada, sobretudo através da presença ou ausência de espermatozóide nos testículos e canais deferentes, sendo relacionada ao aspecto macroscópico conferido pelas modificações apresentadas nos indivíduos frescos (como cor, tamanho, diâmetro e desenvolvimento do espermatóforo no canal deferente) e à relação gonadossomática. Estas análises possibilitaram a caracterização de três estádios de desenvolvimento: I) Imaturo - neste estádio, dois indivíduos foram analisados com comprimento da carapaça variando entre 26,0 e 33,7 mm. Macroscopicamente, os testículos apresentaram-se translúcidos e dificilmente visualizados a olho nu (Fig. 2). Este estádio foi caracterizado pela ausência de espermátides e espermatozóides nos testículos e de espermatozóides nos canais deferentes. A parede do túbulo seminífero está formada por espermatogônia (Fig. 3). Dentro do canal deferente, o espermatóforo apresentou forma de um "C", com concavidade preenchida pela tiflossole e uma matriz espermatofórica acelular (Fig. 4). II) Intermediário - neste estádio foram analisados 46 machos com comprimento da carapaça variando entre 31,2 e 56,0 $\mathrm{mm}$. Macroscopicamente, a gônada apresenta uma cor branco-amarelada ou creme e os canais deferentes são bem perceptíveis (Fig. 5), mas sem aspecto convoluto. Na microfotografia observou-se espermátides e raros espermatozóides espaçados no lume do túbulo seminífero (Fig. 6), enquanto nos canais deferentes, estas células foram ausentes (Fig. 7). A RGS apresentou valor médio de 0,177 \pm 0,060. III) Maturo - neste estádio foram analisados 1668 machos com comprimento da carapaça variando entre 37,0 e 84,0 $\mathrm{mm}$. À vista desarmada, os testículos de cor amarela clara apresentam-se bem maiores que no estádio anterior e os canais deferentes exibem tamanhos e diâmetro consideravelmente maior que o estádio II, com aspecto convoluto e esbranquiçado ou 

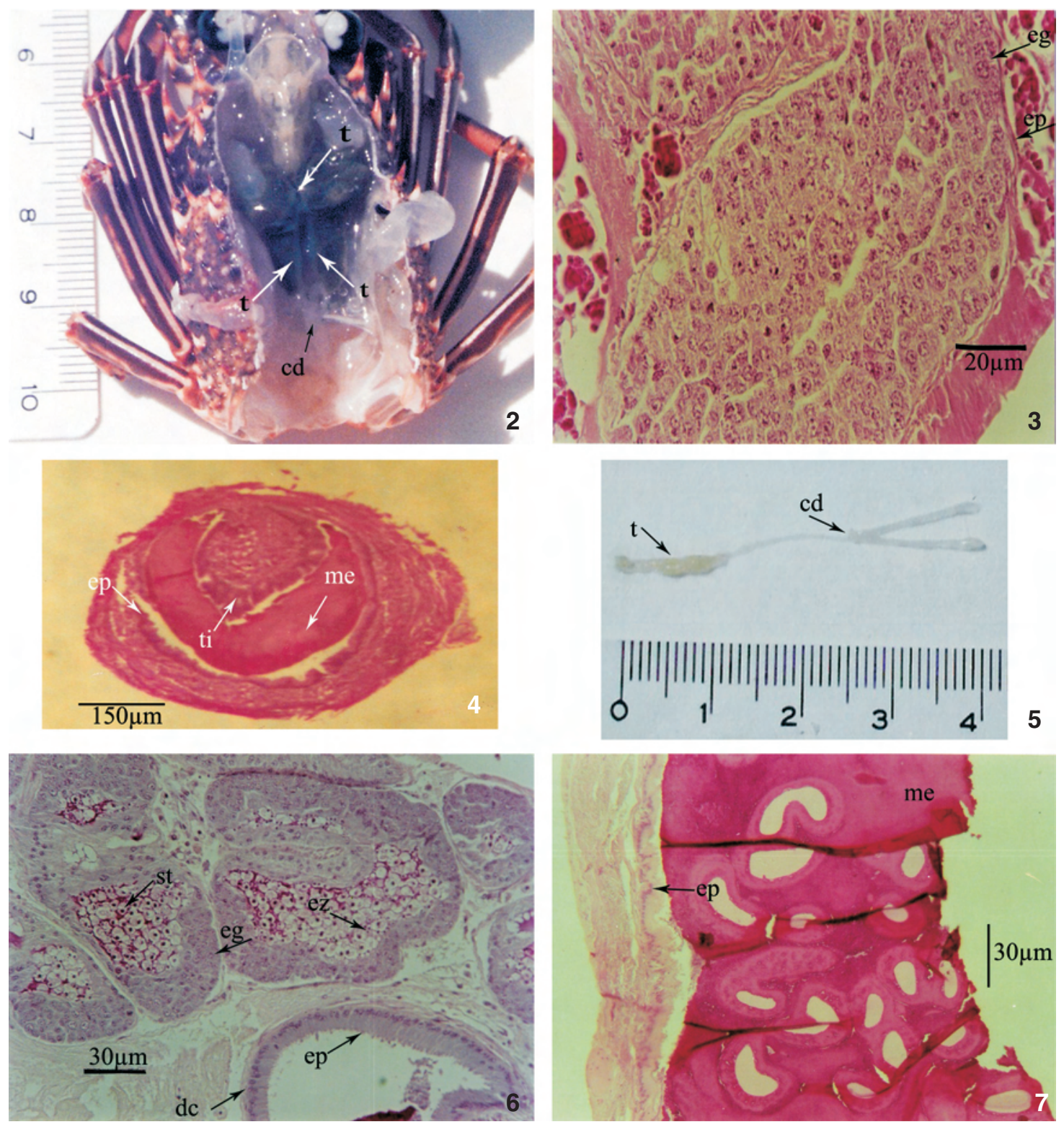

Figuras 2-7 Macroscopia e fotomicrografia de seções transversais e longitudinais dos testículos e canais deferentes de Panulirus echinatus: (2) estádio imaturo; (3) testículos; (4) canal deferente; (5) estádio intermediário: (6) testículos; (7) canal deferente. (cm) Camada muscular, (cd) canal deferente, (dc) ducto coletor, (eg) espermatogônia, (ep) epitélio, (epti) epitélio da tiflossole, (ez) espermatozóide, (me)matriz espermatofórica, (st) espermátide, (t) testículos, (ti) tiflossole.

branco levemente azulado devido à presença de espermatóforos totalmente desenvolvido nas porções mais dilatadas destes canais, delineados pela presença de uma linha hialina (Fig. 8). O estádio maturo foi microscopicamente caracterizado pela presença de espermátides e de agrupamentos de espermatozóides que se concentram no lume dos testículos (Fig. 9) e nos canais deferentes (Figs 10). A parede do canal deferente mediano é com- posta de epitélio pseudo-estratificado colunar secretor que forma a tiflossole. Este epitélio é circundado por músculo circular. O tubo de esperma mostrou-se repleto de espermátides e espermatozóides agrupados, envolto em uma matriz espermatofórica acelular (Fig. 11). A RGS apresentou valor médio de 0,680 \pm 0,207 e maior ganho de peso gonadossomático no estádio III. Pela análise descritiva da variável RGS foi observado que

Revista Brasileira de Zoologia 25 (1): 74-82, March, 2008 

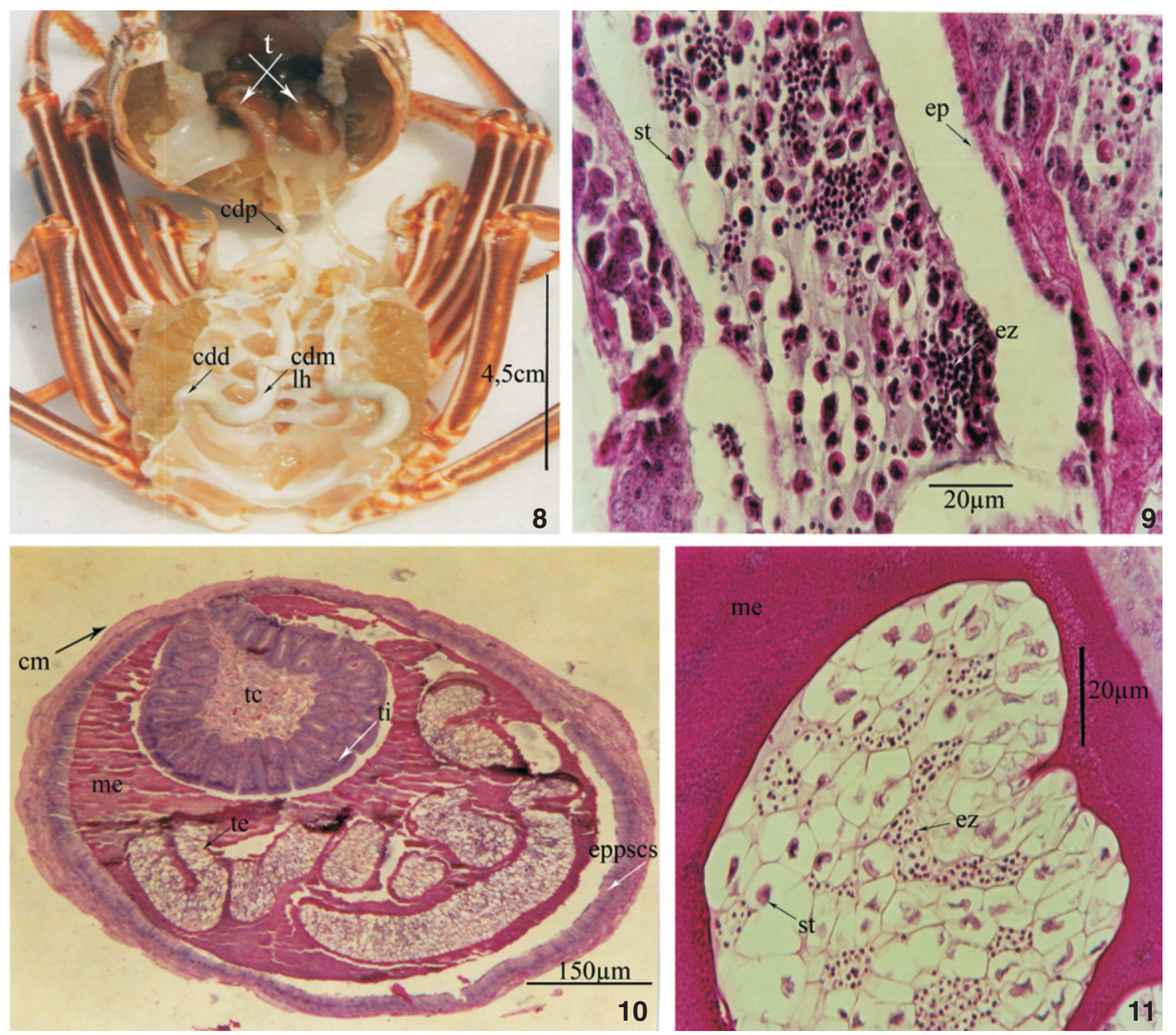

Figura 8-11. Panulirus echinatus matura. (8) Macroscopia e fotomicrografia de seções longitudinais e transversais dos: (9) testículos; (10) canais deferentes; (11) tubo espermatofórico. (cdp) Canal deferente proximal, (cdm) canal deferente mediano, (cdd) canal deferente distal, (eppscs) epitélio pesudo-estratificado colunar secretor, (ez) espermatozóide, (eg) espermatogônia, (lh) linha hialina, (st) espermátide, (me) matriz espermatofórica, (te) tubo de esperma, (ti) tiflossole, (tc) tecido conjuntivo.

seus valores médios $(\bar{x})$ aumentaram com o desenvolvimento até alcançar valor máximo no estádio III (Tab. I).

$\mathrm{Na}$ análise estatística, os dados referentes ao estádio I foram desprezados; para os demais estádios, o tamanho da amostra foi suficiente para garantir a suposição de normalidade envolvida no teste $t$ de igualdade entre médias.
O P-value do teste F foi igual a zero para $\alpha=0,05$, descartando a hipótese de igualdade de variâncias. Obteve-se um intervalo de $95 \%$ de confiança para a diferença entre as médias $\mu_{2}-\mu_{3}$ igual a $[-0,5233 ;-0,4830]$. O P-value do teste $t$ evidenciou diferenças significativas, confirmando que as médias da RGS são diferentes (Tab. I).

Tabela I. Medidas descritivas da relação gonadossomática (RGS) e test t para as diferenças entre as médias de RGS dos estádios II e III de Panulirus echinatus.

\begin{tabular}{|c|c|c|c|c|c|c|c|c|}
\hline Fonte de variação & $\mathrm{N}$ & Mínimo & Máximo & Média & Desvio padrão & Erro padrão da média & Graus de liberdade & Teste $\mathrm{t}$ \\
\hline RGS II & 46 & 0,0579 & 0,3180 & 0,1770 & 0,0595 & 0,0088 & 45 & $-49,62^{*}$ \\
\hline RGS III & 1668 & 0,1401 & 1,9201 & 0,6801 & 0,2074 & 0,0051 & 1667 & \\
\hline
\end{tabular}

* Significativo para $\mathrm{p}<0,05$.

Revista Brasileira de Zoologia 25 (1): 74-82, March, 2008 


\section{DISCUSSÃO}

No presente trabalho, os recifes costeiros de Tamandaré foram considerados áreas de reprodução e alimentação de adultos, pré-adultos e jovens da lagosta P. echinatus. De acordo com Melo (1996) e Holthuis (1991), P. echinatus é uma espécie estritamente costeira e/ou insular. O número de exemplares capturados no estádio intermediário e, sobretudo no estádio imaturo foi decorrente do típico comportamento de refúgio destas lagostas que vivem nas reentrâncias das fendas recifais. Nos indivíduos imaturos, as ecdises são freqüentes, conseqüentemente, eles se refugiam dos predadores, diferindo dos machos adultos que realizam deslocamentos noturnos a procura de alimento. De acordo com Munro (1974) e Briones-Fourzán (1995), os juvenis de Panulirus guttatus (Latreille, 1804) não se encontram facilmente, porém os pré-adultos e adultos são facilmente coletados em recifes de corais. Padilha-Ramos \& BrionesFourZÁn (1997) concluíram que $P$. guttatus é uma espécie residente dos recifes de corais e não migratória. Eles comentaram que em Puerto Morelos, México, os pescadores utilizam um gancho para retirar as lagostas de seu refúgio. P. echinatus se assemelha morfologicamente (HoLthuIs 1991) e em comportamento a $P$. guttatus. As redes de emalhar que foram utilizadas em Tamandaré, PE, emaranham as lagostas espinhosas pelas patas, pelas antenas e pela carapaça.

O trato reprodutor do macho de $P$. echinatus, semelhantemente a outras lagostas, localiza-se na região dorsal e mediana do cefalotórax. Os testículos apresentam aspecto macroscópico similar ao referido por Mota Alves \& Tomé (1966a) para a lagosta $P$. laevicauda. Estes autores relataram que, microscopicamente, o testículo está constituído por uma estrutura tubular, com numerosos túbulos seminíferos de pequena dimensão e de dutos coletores, encontrado em toda a sua extensão. Por outro lado, Matrhews (1951) sugeriu os testículos de Panulirus penicillatus (Oliver, 1791) como uma glândula composta ou racemosa consistindo de dutos coletores que se ramificam e terminam em ácinos; em seções transversais, a porção mediana e posterior do testículo mostraram folículos em vários graus de maturidade. Na porção anterior, MatTHEws (1951) mostrou o epitélio seminífero. O presente trabalho analisou os testículos com o objetivo de investigar, sobretudo a presença ou ausência de espermatozóides. Eles não foram minuciosamente dissecados em todo seu trajeto, portanto túbulo ou túbulos seminíferos e ácinos devem ser investigados em outra proposta de trabalho.

No presente estudo, a sutil mudança de cor dos testículos de translúcido para branco-amarelado e posteriormente amarelo claro e, sobretudo o tamanho, diâmetro e peso dos canais deferentes com espermatóforo desenvolvimento, ou não, quando aliados à presença e/ou ausência de espermatozóides possibilitaram a caracterização dos três estádios de desenvolvimento. Entretanto, foi a partir da análise microscópica que se evidenciou a maturidade dos testículos precedendo a maturidade dos canais deferentes. Um dos estádios mais difíceis de caracterizar foi o intermediário, uma vez que o testículo e o canal deferente não amadureceram sincronicamente. As primeiras células germinativas são as espermatogônias (célula diplóide que, por ocasião da maturidade sexual sofre mitoses sucessivas, originando novas espermatogônias, ou então, pára de se dividir e cresce, tornando-se espermatócito primário); estas células localizam-se na convoluta parede do túbulo seminífero. A presença de espermátides (células haplóides que ao diferenciar-se dará origem aos espermatozóides) e de raros espermatozóides no testículo e sua ausência nos canais deferentes foi o que caracterizou o estádio intermediário. A origem dos espermatozóides ocorreu nos testículos, mas estas células só foram observadas nos canais deferentes quando a espermatogênese estava completa. Sugerindo que os ductos coletores recebem espermatozóides produzidos no túbulo seminífero que posteriormente são transferidos para o canal deferente. Este fato foi previamente comprovado por HinsH \& WALKER (1974) no caranguejo Libinia emarginata Leach, 1815 (Pisidae). A maturidade funcional do macho de P. echinatus completou-se quando espermatozóides estavam presentes tanto nos testículos quanto nos canais deferentes. Este estádio de desenvolvimento foi relacionado macroscopicamente ao aspecto convoluto e esbranquiçado ou branco azulado dos canais deferentes que apresentam considerável mudança no tamanho, diâmetro e peso. Então, está é a principal característica para indicar a maturidade funcional dos machos de P. echinatus. Mota Alves \& Tомé (1966a) relataram que seria praticamente impossível uma classificação em estádios baseada apenas na observação macroscópica dos testículos. E acrescentam, "ainda que o fluir do sêmen, pela pressão nas suas paredes, indique uma fase avançada de maturação gonadal, mesmo assim, não é possível determinar com precisão o grau de desenvolvimento em que os testículos se encontravam". Assim, estes autores tiveram que recorrer aos cortes histológicos para determinar com segurança os estádios de desenvolvimento gonadal dos machos de $P$. laevicauda. Segundo HEydorn (1969), as mudanças sazonais na aparência macroscópica dos testículos e canais deferentes da lagosta $P$. homarus não foram acentuadas e, portanto não deram indicação confiável dos estádios no ciclo reprodutivo. De acordo com FARMer (1974), que investigou a reprodução da lagosta Nephrops norvegicus (Linnaeus, 1758) (Nephropidae) machos com $1,8 \mathrm{~cm}$ de carapaça têm aparentemente espermatozóides já desenvolvidos nos túbulos seminíferos, mas não apresentam normalmente espermatóforos desenvolvidos nos canais deferentes. Segundo BerRy \& HEYdorn (1970) e RAdHA \& Subramoniam (1985), a porção mais dilatada do canal deferente, delineada pela linha hialina, é a que armazena espermatóforos completamente desenvolvido. Este fato foi considerado no presente estudo, assim, esta região foi selecionada para as análises histológicas. Nos canais deferentes, a linha hialina está unida com a tiflossole (MatTHEws 1951). Esta linha segundo Mota-Alves \& Tomé (1966b) corresponde ao músculo associado a esta glândula. HaLey (1984) ao estudar a lagosta 
vermelha Enoplometopus occidentalis (Randall, 1840) (Enoplometopidae) observou que até antes da ejaculação do espermatóforo, a porção distal do canal deferente não apresentou aspecto esbranquiçado. De acordo com FARMER (1974), em $N$. norvegicus a abertura genital encontra-se normalmente fechada por uma fina membrana, que se rompe quando ocorre a liberação do espermatóforo. HEYDORN (1965) estudando a biologia reprodutiva da lagosta de rocha Jasus lalandii (H. MilneEdwards, 1837) (Palinuridae) utilizou o peso dos canais deferentes como indicador do peso das gônadas. De acordo com Heydorn (1969) que também investigou a biologia da lagosta $P$. homarus, o início da maturidade gonadal foi indicado pelo estádio de desenvolvimento dos canais deferentes. Estes se tornam claramente visíveis a olho nu, logo que eles contêm fluido seminal. Minagawa \& Higuchi (1997) que também estudaram a reprodução de $P$. homarus, afirmaram que a presença de espermatóforo desenvolvido nos canais deferentes tem sido considerada evidência de maturidade gonadal, ou segundo Micheli et al. 1990 e HaEfNER (1985) que estudaram os Brachyura evidência de maturidade funcional. NAKAMUra (1990) também constatou que o canal deferente de Panulirus japonicus (Von Siebold, 1824) mudou de tamanho com a maturação. Desta forma, os dados analisados como aspecto geral do trato reprodutor e, sobretudo a presença ou ausência de espermatozóide, somada aos valores médios da RGS serviram para embasar a presente proposta. Segundo MatThews (1951), Berry \& Heydorn (1970) e Radha \& Subramoniam (1985) que pesquisaram a origem e a natureza do espermatóforo das lagostas da família Palinuridae, o espermatóforo completamente desenvolvido no canal deferente consiste de um tubo espermatofórico contínuo altamente convoluto, contendo massa de esperma, matriz gelatinosa protetora e matriz adesiva. O peso do canal deferente (Gosselin et al. 2003) ou o tamanho do espermatóforo (MacDiarmid \& Butler 1999) estão correlacionados com o comprimento do corpo dos machos. No presente trabalho, os valores médios da relação gonadossomática (RGS) que refletem o peso dos órgãos reprodutivos como porcentagem do peso do corpo da lagosta foram máximos para os indivíduos maturos de $P$. echinatus, porque o canal deferente contendo espermatóforo já estava totalmente desenvolvido. Por outro lado, esses valores evidenciaram que o incremento de peso dos testículos e canais deferentes do estádio I (imaturo) para o estádio II (intermediário) em $P$. echinatus ocorreu de uma forma sutil, porque estas estruturas ainda estavam imaturas e/ou em processo de maturação. A RGS mostrou-se relacionada com o estádio de maturidade, e $P$. echinatus atingiu a maturidade funcional no estádio III quando os valores médios da relação gonadossomática foi $0,680 \pm$ 0,207. Neste estádio, o tamanho mínimo dos machos foi 37 $\mathrm{mm}$, estando de acordo com o tamanho médio de primeira maturidade gonadal estimado por BARRETo et al. (2006). Segundo IsAAC-NAHUM \& VAZZOLER (1987) que estudaram a biologia reprodutiva do peixe teleósteo Micropogonias furniere (Desmarest,
1823) (Scianidae) apesar de existirem as diferenças individuais, a RGS é uma constante para um determinado estádio de maturidade, qualquer que seja o peso do exemplar. Em P. echinatus, o peso dos testículos e canais deferentes foi baixo até a maturidade funcional ser atingida (estádio III). A diferença nas médias da RGS foi comprovada após os testes realizados em nível de significância de 0,05 (a chance de cometer o erro de rejeitar Ho sendo ela verdadeira). Desta forma pode-se estar 95\% certos de que as diferença constatadas nas médias da RGS é um efeito real. Logo, a RGS corroborou os estádios de maturidade e pode ser utilizada como indicadora dos estádios de desenvolvimento para P. echinatus.

O testículo amadureceu primeiro que o canal deferente, logo, a ausência de espermatozóides nos canais deferentes foi o que caracterizou o estádio intermediário. A maturidade gonadal foi comprovada quando os testículos e canais deferentes apresentaram considerável mudança no tamanho, diâmetro e peso em relação aos estádios anteriores e os canais deferentes exibiram aspectos convolutos e esbranquiçados (devido à retenção do espermatóforo completamente desenvolvido); microscopicamente, este estádio maturo foi caracterizado pela presença simultânea de espermatozóides nos testículos e canais deferentes. Estas características foram observadas, sobretudo em indivíduos com comprimento do cefalotórax superiores a $37 \mathrm{~cm}$. Este pode ser considerado o tamanho de primeira maturidade dos machos de P. echinatus.

\section{AGRADECIMENTOS}

Em memória à Ana E.A. de M. Vazzoler, minha orientadora. Agradecemos a ajuda prestada por Ana V.P. Lima e Alexandre A. Oliveira na análise histológica. A Diógenes L. de Mota pelas microfografias e a informatização dos dados da RGS ao estatístico Alberto P. Barros (CEFET-PB) e à Maria de L. ZaniTeixeira. Esta pesquisa foi financiada pelo programa CAPES/ PICDT da Universidade Federal de Pernambuco e tema de tese de doutorado no Instituto Oceanográfico (USP).

\section{LITERATURA CITADA}

Barreto, A.V.; C.T.C. Ivo \& M. Katsuragawa. 2003. Comprimento médio da primeira maturidade gonadal dos machos da lagosta pintada, Panulirus echinatus (Smith, 1869), em recifes costeiros de Tamandaré, Pernambuco, Brasil. Boletim Técnico Científico CEPENE 11 (1): 91-97.

Berry, P.F. \& A.E.F. Heydorn. 1970. A comparison of the spermatophoric masses and mechanisms of fertilization in Southern African spiny lobsters (Palinuridae). Investigational Report Division of Sea Fisheries South Africa 25: 1-18.

Briones-FourZán, P. 1995. Difencias Y similitudes entre Panulirus argus y Panulirus guttatus, dos espécies de langosta comunes en el Caribe Mexicano. Revista Cubana Investigaciones Pesqueiras: 14-20. 
Castiglioni, D.S.; G.T. Oliveira \& G. Bond-Buckup. 2006. Dinâmica do Desenvolvimento das gônadas de Parastacus varicosus (Crustcea, Decapoda, parastacidae). Iheringia, Série Zoologia, 96 (4): 413-417.

Dudenhausen, E.E. \& P. TALвот. 1983. An ultrastrutural comparison of soft and hardened spermatophores from the crayfish Pacifastus leniusculus, DANA. Canadian Journal Zoology 61: 182-194.

FARMER, A.S.D. 1974. Reproduction in Nephrops norvegicus (Decapoda: Nephropidae). Journal of Zoology 174: 61-183.

Gosselin, T.; B. Saint-Marie \& L. Bernatchez. 2003. Patterns of sexual cohabitation and female ejaculate storage in the American lobster (Homarus americanus). Behavioral Ecology and Sociobiology 55: 151-160.

Haefner JR, P.A. 1985. Morphometry, reproduction, diet and epizoites of Ovalipes stephensoni Williams, 1976 (Decapoda, Brachyura). Journal of Crustacean Biology 5 (4): 658-672.

Haley, S.R. 1984. Spermatogenesis and spermatophore production in the Hawaiian red lobster Enoplometopus occidentalis (Randall) (Crustacea, Nephropidae). Journal of Morphology 180: 181-193.

Heydorn, A.E.F. 1965. The rock lobster of the South African west coast Jasus lalandi (H. Milne-Edwards). 1. Notes on the reproductive biology and the determination of minimum size limits for commercial catches. Investigational Report, Division of Sea Fisheries, South Africa 53: 1-32.

HEydorn, A.E.F. 1969. Notes on the Biology of Panulirus homarus and on length/weight relationships of Jasus lalandii. Investigational Report, Division of Sea Fisheries, South Africa 69: 1-27.

Hinsch, G.W. \& C.E. McKnight. 1988. The vas deferens of the Spanish lobster, Scyllarus Chacei. Internacional Journal of Invertebrate Reproduction and Development 13: 267-280.

Hinsch, G.W. \& M.H. Walker. 1974. The vas deferens of the spider crab, Libinia emarginata. Journal of Morphology 143: $1-19$.

Holthuis, L.B. 1991. FAO Species Catalogue. Marine lobsters of the world. An annotated and illustrated catalogue of species of interest to fisheries known to date. FAO Fisheries Synopsis 13 (125): 1-292.

IsAAC-NAHUM, V.J. \& A.E.A.M. VAZzoler. 1987. Biologia reprodutiva de Micropogonias furnieri (Desmarest, 1823) (Teleostei, Scianidae) 2. Relação gonadossomática, comprimento e peso dos ovários como indicador do período de desova. Boletim do Instituto Oceanográfico 35 (2): 123-134.

Junqueira, L.C. \& L. Carneiro. 1995. Histologia básica. São Paulo, Guanabara, 433p.

KoA-Jen, J. 1993. Growth of the spiny lobster Panulirus homarus (Linnaeus, 1758), depending on sex and influenced by reproduction (Decapoda, Palinuridae). Crustaceana 64 (1): 18-23.

Kooda-Cisco, M. \& P. TALвот. 1986. Ultrastructure and role of the lobster vas deferens in Spermatophore formation: the proximal segment. Journal of Morphology 188: 91-103.
LindBeRG, R.G. 1955. Growth, population dynamics and field behavior in the spiny lobster, Panulirus interruptus (Randall). University of California Publications in Zoology 59 (6): 157-248.

Mabessone, J.M. \& P.N. Coutinho. 1970. Litoral and shallow marine Geology of Northearn and Northeastern Brazil. Trabalhos Oceanográficos da Universidade Federal de Pernambuco 2: 1-214.

Mac Diarmid, A.B \& M.J. Butler IV. 1999. Sperm economy and limitation in spiny lobsters. Behavioral Ecology and Sociobiology 46: 14-24.

Martin, G.G.; C. Herzig \& G. Narimatsu. 1987. Fine structure and histochemistry of the freshly extruded and hardened spermatophore of the spiny lobster, Panulirus interruptus. Journal of Morphology 192: 237-246.

MatThews, D.C. 1951. The origen, development, and nature of the spermatophoric mass of the spiny lobster, Panulirus penicillatus (Oliver). Pacific Science 5: 359-369.

Melo, G.A.S. 1999. Manual de identificação dos Crustacea Decapoda do litoral brasileiro: Anomura, Thalassinidea, Palinuridea e Astacidea. São Paulo, Plêiade, 551p.

Micheli, F.E.; F. Gerarad \& M.M. Vannini. 1990. Growth and reproduction in the freshwater crab, Potamon fluviatile (Decapode, Brachyura). Freshwater Biology 23: 491-503.

Minagawa, M. \& S. Higuchi. 1997. Analysis of size, gonadal maturation, and functional maturity in the spiny lobster Panulirus japonicus (Decapoda: Palinuridae). Journal of Crustacean Biology 17 (1): 70-80.

Mota-Alves, M.I. \& G.S. Tomé. 1965. Estudo sobre as gônadas da lagosta Panulirus argus (Latreille). Arquivo Estudo de Biologia Marinha 5 (1): 15-26.

Mota-Alves, M.I. \& G.S. Tomé. 1966a. Estudo sobre as gônadas da lagosta Panulirus laevicuada (Latreille). Arquivo Estudo de Biologia Marinha 6 (1): 1-9.

MotA-Alves, M.I. \& G.S. Tomé. 1966b. Observação sobre a origem e desenvolvimento da massa espermatofórica de Panulirus laevicuada (Latreille). Arquivo Estudo de Biologia Marinha 6 (1): 99-102.

MunRo, J.L. 1974. The biology, ecology and bionomics of spiny lobster (Palinuridae), spider crabs (Majidae) and other crustacean resources, p. 206-222. In: J.L. MunRo (Ed.). Caribbean Coral Reef Fishery Resources. Jamaica, University West Indies, $2^{\text {nd }}$ ed., $276 \mathrm{p}$.

Nakamura, K. 1990. Maturation of the spiny lobster Panulirus japonicus. Memoirs of the Faculty of Fisheries, Kagoshima University 39: 129-135.

Padilha-Ramos, S. \& P. Briones-Fourzán. 1997. Características biológicas de las langostas (Panulirus spp.) provenientes de las capturas em Puerto Morelos, Quintanar Roo, México. Ciencias Marinas 23 (2): 175-193.

Radha, T. \& T. Subramoniam. 1985. Origin and nature of spermatophoric mass of the spiny lobster Panulirus homarus. Marine Biology 86 (1): 13-1.

Revista Brasileira de Zoologia 25 (1): 74-82, March, 2008 
Rebouças, A.C. 1966. Sedimentos da Baía de TamandaréPernambuco. Trabalhos Oceanográficos da Universidade Federal Pernambuco 7/9: 187-206.

Sokolowicz,C.C.; G. Bond-Buckup \& L. Buckup. 2006 Dynamics of gonadal development of Aegla platensis Schmitt (Decapoda, Anomura, Aglidae). Revista Brasileira de Zoologia 23 (4): 1153-1158.

Talbot, P. \& D. BEach. 1989. Role of the vas deferens in the formation of the spermatophore of the crayfish (Cherax). Journal of Crustacea Biology 9 (1): 9-24.

VAzzoler, A.E.A.M. 1996. Biologia e reprodução de peixes teleósteos: teoria e prática. Maringá, Editora da Universi- dade Estadual de Maringá, 169p.

Vazzoler, A.E.A.M.; M. Caraciolo-Malta \& S.A. Amadio 1989a. Aspectos biológicos de peixes amazônicos. XI. Reprodução das epécies do gênero Semaprochilodus (Characiformes, Prochilodontidae) do baixo rio Negro, Amazonas, Brasil. Revista Brasileira de Biologia 49 (1): 165-173.

Vazzoler, A.E.A.M.; M.Caraciolo-Malta \& S.A. Amadio. 1989b. Aspectos biológicos de peixes amazônicos. XII. Indicadores quantitativos do período de desova das espécies do gênero Semaprochilodus (Characiformes, Prochilodontidae) do baixo rio Negro, Amazonas, Brasil. Revista Brasileira de Biologia 49 (1): 175-181.

Received in 22.VIII.2007; accepted in 05.III.2008. 